\title{
Trace Element Content of Monovarietal and Commercial Portuguese Olive Oils
}

\author{
Irene Gouvinhas ${ }^{1 \# *}$, Nelson Machado ${ }^{1 \#}$, Maria Cunha², Marisa Pereira², Carlos Matos ${ }^{2}$, \\ Sónia Gomes ${ }^{3}$, João Lopes ${ }^{4}$, Paula Martins-Lopes ${ }^{3}$ and Ana I.R.N.A Barros ${ }^{1}$ \\ ${ }^{1}$ CITAB - CITAB, University of Trás-os-Montes and Alto Douro, 5001-801 Vila Real, Portugal \\ ${ }^{2}$ Chemistry Department, University of Trás-os-Montes and Alto Douro, 5000-801 Vila Real, Portugal \\ ${ }^{3}$ DGB- Department of Genetics and Biotechnology- University of Trás-os-Montes and Alto Douro (CGB-UTAD/IBB), P.O. Box 1013, 5000-801, \\ Vila Real, Portugal \\ ${ }^{4}$ DRAPN- Direção Regional de Agricultura e Pescas do Norte, 133, 5370-347, Mirandela, Portugal \\ " Both authors contributed equally to this work
}

\begin{abstract}
Olive (Olea europaea L.) represents one of the most important and ancient crops in the Mediterranean countries, being widely known due to the optimal organoleptic characteristics of its oil, besides the important health benefits assigned to this product in the last few years. Since olive oil composition, respecting specific trace elements, has a direct impact on the quality and safety of this product, eleven monovarietal and twelve commercial olive oils were analysed spectrometrically concerning their metal composition. Regarding quality parameters, the monovarietal olive oils display larger quantities of $\mathrm{Mg}, \mathrm{Fe}, \mathrm{Mn}$, while the commercial samples are characterized by greater amounts of $\mathrm{Na}, \mathrm{Ca}, \mathrm{Cu}$ and $\mathrm{Zn}$. In which respects to safety parameters, the commercial samples present higher values for $\mathrm{Al}$ and $\mathrm{Pb}$, and lower quantities of $\mathrm{Cd}$, respecting the monovarietal ones. The assessment of the values observed for the trace elements, resorting to multivariate statistical methods, allowed to clearly distinguish the type of olive oil production-monovarietal or commercial blend. For this purpose, besides Cluster analysis, the data have been subjected to Principal Component Analysis-undertaken for either all the evaluated parameters simultaneously, or the quality/safety parameters separately, both data sets allowing the discrimination of the samples.
\end{abstract}

Key words: olive oil, trace elements, commercial, monovarietal, quality, safety

\section{INTRODUCTION}

Olive (Olea europaea L.) constitutes an ancient crop in the Mediterranean countries, its growth being widely established throughout this region. The value of this crop lies on the exceptional sensory quality of its oil, in comparison to other oils and fats, besides the health benefits that have been lately related to this product in the last few years, leading its consumption to be increasingly widespread around the world ${ }^{1)}$. The increasing demand for olive oil, lead to a major growth of the production in order to fulfill the costumers' demand, with the quality control of this product becoming an issue. Therefore, quality and security parameters have been established by the EU, which produced legislation in order to limit the quantities of heavy metals, respecting elements such as lead, cadmium and mercury, protecting the costumers' main interest, since these elements represent a public health issue $\mathrm{e}^{2)}$.
Therefore, the quantitative evaluation of trace elements in edible oils represents a concern of considerable interest, due to the potential toxicity of those elements, while the presence of some other metallic species can possibly affect the overall quality (flavour and stability) of this product ${ }^{3)}$. The presence of metals in olive oil depends on a plethora of events, namely, the extraction technology, genotype of the olive tree, usage of fertilizers and pesticides during growth, or by contamination from the metal processing equipment and by environmental exposure ${ }^{4)}$. The latter is a result of natural deposition from plants and bioaccumulation that is directly associated with the soil natural metal sources and environmental pollution.

The concentrations of these metals represent important indicators of olive oil quality regarding freshness, storability and toxicity ${ }^{5)}$. Trace elements can be classified as essentials $(\mathrm{Cu}, \mathrm{Zn}, \mathrm{Mn}, \mathrm{Fe}, \mathrm{Mn})$, probably essentials (Vn, Co) and

\footnotetext{
*Correspondence to: Irene Gouvinhas, CITAB-CITAB, University of Trás-os-Montes and Alto Douro, 5001-801 Vila Real, Portugal E-mail: igouvinhas@utad.pt Accepted July 14, 2015 (received for review April 29, 2015)

Journal of Oleo Science ISSN 1345-8957 print / ISSN 1347-3352 online http://www.jstage.jst.go.jp/browse/jos/ http://mc.manusriptcentral.com/jjocs
} 


\section{Gouvinhas, N. Machado and M. Cunha et al.}

potentially toxic (As, $\mathrm{Cd}, \mathrm{Pb}, \mathrm{Al}$ ). However, essential metals can be also responsible for toxic effects whenever their intake is excessive ${ }^{6)}$. Furthermore, some metals (e.g. Cu, $\mathrm{Zn}, \mathrm{Fe}, \mathrm{Mn}, \mathrm{Ni}$ ) accelerate the oxidation processes in edible oils, thus, having a negative effect on their sensory quality $^{7)}$.

Additionally, the presence of these trace elements might be also considered for the traceability of olive oil, respecting characteristics such as origin, olive cultivars and extraction processes. The chemical components to be considered for the traceability of this product are those unaffected by transportation and milling of olives, as well as storage and retailing of olive oil ${ }^{8)}$. In the last recent years, several chemical methodologies, such as inductively coupled plasma (ICP) combined with atomic emission spectrometry or mass spectrometry, and atomic absorption spectrometry (AAS), have been used to determine trace elements in olive oils in order to assess their authenticity and geographical traceability ${ }^{9-12)}$, as well as to detect possible adulterations ${ }^{13)}$.

Despite the inexistence of particular compounds in the oil directly related to the geographical origin, each one of its components might be partially affected by the characteristics of the growing area and the cultivars used. Trace elements and stable radio-isotope ratios have been widely considered in the determination of geographical provenience of several food products and have been applied specifically for olive oil traceability purposes ${ }^{10)}$. Within this scope, multivariate analysis approaches, such as Principal Components Analysis $(\mathrm{PCA})^{14)}$ or Cluster Analysis ${ }^{15)}$ have proven to be prolific in generating reliable traceability systems for foodstuffs, including the discrimination of cultivars or maturation stages in different olive oils, allowing the simultaneous evaluation of several distinct parameters for this purpose ${ }^{16)}$.

Even though some studies concerning the determination of trace elements in edible oils can be found in the presently available literature, to the best of our knowledge, there is no study available, respecting the quantification of trace elements in commercial and monovarietal Portuguese olive oils. Therefore, in the present work, the concentration of eleven metals, related to quality and safety parameters, have been assessed in eleven monovarietal olive oils, produced within the scope of this study, and twelve commercial olive oils available in the market. Multivariate analysis approaches were employed to verify the discrimination of the different olive oils, resorting only to the trace elements determined in this work.

\section{MATERIAL AND METHODS}

\subsection{Reagents}

Hydrogen peroxide(30\% p.a.), concentrated hydroclo- ridric acid and nitric acid (65\% p.a.) were acquired from Merck (Darmstadt, Germany). Ultrapure water was obtained from a Millipore water purification system. The standard solutions used for calibration, for the elemental determinations, were obtained by diluting a stock solution of $1000 \mathrm{mg} / \mathrm{L}$ of each given element, supplied by Merck (Darmstadt, Germany).

\subsection{Olive oil samples}

Portuguese monovarietal olive oil samples were obtained from olives harvested from certified orchards of the following olive cultivars: Azeiteira, Blanqueta, Carrasquenha, Cobrançosa, Cordovil Castelo Branco, Galega, Redondil, Cordovil Serpa, Verdeal Serpa grown in the Alentejo Region, at the fields of the National Plant Breeding Station in Elvas, Portugal, while the Madural and Redondal cultivars were grown in Trás-os-Montes Region, in the experimental fields of DRAPN (Direção Regional de Agricultura e Pescas do Norte), Mirandela, Portugal.

The codes used throughout the present work, corresponding to each one of these cultivars, are assigned in Table 1. All monovarietal olive oil samples were produced in the crop season 2012/2013 in the Department of Oliviculture in National Plant Breeding Station in Elvas, Portugal, using approximately $9.0 \mathrm{~kg}$ of olive fruits of each cultivar, from certified groves, with the olives being transformed immediately after harvest, resorting to cold centrifugation. This production was conducted from the end of November to the beginning of December, due to the different maturation periods of the distinct cultivars. Three olive oil samples were produced for each cultivar $(3.0 \mathrm{~kg}$ of olive fruits used per olive oil sample produced). Olive oil extraction was performed using an Abencor system(INIA I.P., Elvas, Portugal) and all samples were transferred into dark glass bottles and stored in the dark at $4^{\circ} \mathrm{C}$ until chemical analysis.

Commercial olive oils were bought at local markets, stored at $4{ }^{\circ} \mathrm{C}$, and analysed within a few days from the purchase. The origin of the commercial olive oils assessed, as well as the code assigned to each one in these work in are indicated in Table 1, which summarizes all the monovarietal and commercial samples of olive oils under study. In all the commercial samples acquired, the oil was obtained exclusively by mechanical means. The samples denoted as Com 7 and Com 8, are the only ones corresponding to olive oils obtained from biological agriculture.

\subsection{Quantification of the Trace Elements}

\subsubsection{Sample preparation}

Prior to the analyses each sample was vigorously shaken. An aliquot $(0.5 \mathrm{~g})$ of sample was weighed directly into the digestion vessels. The digestion was performed by adding $\mathrm{HNO}_{3}(1.0 \mathrm{~mL})$ and $\mathrm{H}_{2} \mathrm{O}_{2}(5.0 \mathrm{~mL})$ to each oil sample. The mixture was left at room temperature with a marble (pre- 
Table 1 Code and PDO region for eleven small scale produced monovarietal obtained olive oils and twelve purchased commercial ones.

\begin{tabular}{|c|c|c|c|}
\hline & Olive oil denomination & Code & PDO region \\
\hline \multirow{11}{*}{ 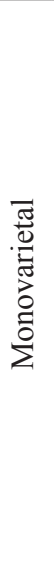 } & Azeiteira & $\mathrm{AZ}$ & Alentejo \\
\hline & Blanqueta & $\mathrm{BL}$ & North Alentejo \\
\hline & Carrasquenha & CAR & Alentejo (Elvas and Campo Maior) \\
\hline & Cobrançosa & $\mathrm{COB}$ & Trás-os-Montes. Alentejo. Ribatejo. Beiras \\
\hline & Cordovil de Castelo Branco & $\mathrm{CCB}$ & Beira Interior \\
\hline & Cordovil de Serpa & $\mathrm{CS}$ & Alentejo (Serpa and Moura) \\
\hline & Galega & GAL & Alentejo. Ribatejo. Beiras \\
\hline & Madural & MAD & Trás-os-Montes \\
\hline & Redondal & REDA & Trás-os-Montes \\
\hline & Redondil & REDI & Alto Alentejo \\
\hline & Verdeal de Serpa & VER & Alentejo (Serpa) \\
\hline \multirow{12}{*}{ 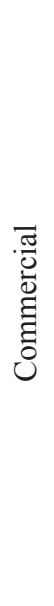 } & Oliveira da Serra: special (bottle) & Com 1 & Not applicable \\
\hline & Oliveira da Serra: selection (bottle) & Com 2 & Not applicable \\
\hline & Oliveira da Serra: classic (tetra-pack) & Com 3 & Not applicable \\
\hline & Gallo: classic (bottle) & Com 4 & Not applicable \\
\hline & Gallo: classic (can) & Com 5 & Not applicable \\
\hline & Casal da Vilariça (bottle) & Com 6 & Trás-os-Montes \\
\hline & Alfandagh $($ ac. $<0.7 \%)$ (bottle) & Com 7 & Trás-os-Montes \\
\hline & Alfandagh (ac. $<0.3 \%)$ (bottle) & Com 8 & Trás-os-Montes \\
\hline & Quinta do Bispado (bottle) & Com 9 & Trás-os-Montes \\
\hline & Herdade do Esporão-Galega (bottle) & Com 10 & Not applicable \\
\hline & Azeite de Moura (bottle) & Com 11 & Alentejo \\
\hline & Casa Grande (bottle) & Com 12 & Trás-os-Montes \\
\hline
\end{tabular}

venting evaporation) for 24 hours, and afterwards, the marble removed and the samples left overnight at room temperature. After this period the sample was heated using a block heater at $50^{\circ} \mathrm{C}$ during $1 \mathrm{~h}$ followed by $100^{\circ} \mathrm{C}$ during $1 \mathrm{~h}$ (temperature at which the release of Nitric Oxide brown fumes starts), $120^{\circ} \mathrm{C}$ during $1 \mathrm{~h}$ and finally left overnight at $155^{\circ} \mathrm{C}$ (usual time needed to obtain a clear digestion mixture), or until the solution was clear, with a glass marble on the top of the culture tube (to avoid drying before digestion and sample charring). After this period the glass marbles were removed, and the contents were dried at $155^{\circ} \mathrm{C}$. After cooling to room temperature, $10.0 \mathrm{~mL}$ of $\mathrm{HNO}_{3}$ matrix solution $(1.5 \mathrm{~mL}$ of acid to $1000 \mathrm{~mL}$ of water) was added to the digested samples and stirred. Some of the solutions were diluted in order to allow the determination of the respective metals. All samples were analyzed in triplicate.

2.3.2 Instrumentation

In the present work, $\mathrm{Na}, \mathrm{Cu}$ and $\mathrm{K}$ were determined by flame atomic emission spectrometry and $\mathrm{Ca}, \mathrm{Mg}, \mathrm{Fe}$ and $\mathrm{Zn}$ metals were analyzed by flame atomic absorption spec- trometry (Thermo Scientific ICE 3000). Mn, Al, Cd and Pb were analyzed by atomic absorption spectrometry in graphite furnace (Unicam 939 AA spectrometer, GF90 furnace). Each run of samples was preceded by calibration using aqueous mixed standards prepared in $\mathrm{HNO}_{3}(1.0 \mathrm{M})$. For this purpose, five different dilutions of standards were used, besides the blank, with the range of concentrations being selected according to the expected concentrations of the elements of interest.

\subsection{Statistical and Multivariate analyses}

Two multivariate approaches have been used, Principal Components Analysis (PCA) and Custer analysis. The former consists on a multidimensional statistical technique, which allows to transform $\boldsymbol{n}$ independent variables into $\boldsymbol{p}$ new independent and non-correlated variables, by means of linear regression over the $\boldsymbol{n}$ independent variables, $\boldsymbol{p}$ being smaller than $\boldsymbol{n}^{17}$. Cluster analysis enables the assessment of natural groups or clusters over $\boldsymbol{n}$ independent variables, with a measure of similarity determining if the observations (samples) belong to the same, or distinct 


\section{Gouvinhas, N. Machado and M. Cunha et al.}

groups (clusters) ${ }^{17)}$.

Data were processed using the OriginPro 9.1 (OriginLab, Northampton, USA). Analysis of variance (ANOVA) and a multiple range test (Tukey' s test) were carried out. Spearman's correlation analysis was performed to corroborate relationships between selected parameters. Principal component analysis was carried out using the analytical data as variables, without solution rotation. This approach was undertaken using all the parameters assessed simultaneously, as well as just for the quality/safety parameters separately. Cluster analysis was applied to the standardized data, resorting to all the analytical parameters assessed (normalized to 0.1 ), in order to obtain hierarchical associations employing Euclidean distance and Ward's method, as dissimilarity measure and amalgamation rule, respectively.

\section{RESULTS AND DISCUSSION}

\subsection{Metal composition}

Commercial and monovarietal olive oil samples have been assessed in which respects to their contents in trace elements, which were determined, and analyzed separately according to their status as quality $(\mathrm{Ca}, \mathrm{Fe}, \mathrm{K}, \mathrm{Mg}, \mathrm{Mn}, \mathrm{Na}$ and $\mathrm{Zn}$ ) or safety ( $\mathrm{Al}, \mathrm{Cd}$ and $\mathrm{Pb}$ ) parameters.

The values observed for the quality parameters are presented in Table 2. The Ca levels ranged between not detectable and $0.08 \pm 2.4 \mathrm{E}^{-3} \mathrm{mg} / \mathrm{g}$. Overall, the commercial olive oil samples presented higher levels of this metal. In comparison with the literature, the levels of $\mathrm{Ca}$ in the monovarietal samples presented similar values $\left(0.01 \mathrm{mg} / \mathrm{g}^{18}\right.$; $\left.0.0185 \mathrm{mg} / \mathrm{g}^{19)}\right)$. Benincasa et al. determined some elements by ICP-MS in monovarietal olive oils (Carolea and Coratina cultivars), obtained from different regions, registering Ca values similar to the presently observed ones $\left(0.0018-0.027 \mathrm{mg} / \mathrm{g}^{20)}\right)$, in a work where the oils were extracted in a laboratory scale hammer mill. Moreover, the commercial samples presented values up to forty times higher (Com 3), respecting the monovarietal ones, and similar to those reported by Mendil et $a .^{21)} 0.076 \mathrm{mg} / \mathrm{g}$, which assessed this element in commercial olive oil samples.

Iron $(\mathrm{Fe})$ constitutes an important content, respecting foodstuffs, once it is linked to several hematological diseases such as anemia ${ }^{22)}$. Therefore, it is important to consider this element in food composition. The level of Fe content varies between $3.3 \mathrm{E}^{-4} \pm 0.00$ and $53 \mathrm{E}^{-4} \pm 4.1 \mathrm{E}^{-5} \mathrm{mg} / \mathrm{g}$. These values are in good agreement with previous reports (18-20, 23). However, Zhu et $a l^{24)}$ and Mendil et $a l .{ }^{21)}$ reported considerably higher values of $341 \mathrm{E}^{-4} \mathrm{mg} / \mathrm{g}$ and $139 \mathrm{E}^{-3} \mathrm{mg} / \mathrm{g}$, respectively.

The $\mathrm{K}$ level in olive oil samples ranged between not detectable and $0.05 \pm 6.9 \mathrm{E}^{-3} \mathrm{mg} / \mathrm{g}$, with all monovarietal samples and four commercial samples presenting higher concentrations than those reported in the Table of Food Composition of Denmark (DTU-TCAD) ${ }^{18)}$, furthermore, other research works concerning commercial olive oils have reported appreciably lower values of $2.9 \mathrm{E}^{-4} \mathrm{mg} / \mathrm{g}^{23)}$ and $2.14 \mathrm{E}^{-3} \mathrm{mg} / \mathrm{g}^{21)}$. Also the concentrations of $\mathrm{Mg}$, in all the olive oil samples, were significantly higher than those reported by Benincasa et al. in monovarietal samples ${ }^{20)}$, and Cindric et $a l^{23)}$ and Mendil et al. in commercial ones ${ }^{21)}$, ranging between 0.02 and $0.04 \mathrm{mg} / \mathrm{g}$. Respecting $\mathrm{Mn}$, its content ranged between $0.10 \pm 1.2 \mathrm{E}^{-4}$ and $0.16 \pm 5.3 \mathrm{E}^{-3}$ $\mu \mathrm{g} / \mathrm{g}$, with the exception of Com 3 , which presented a lower quantity, $0.06 \pm 7.7 \mathrm{E}^{-4} \mu \mathrm{g} / \mathrm{g}$, similar to the reported values of $0.06 \mu \mathrm{g} / \mathrm{g}^{20)}$ and $0.08 \mu \mathrm{g} / \mathrm{g}^{23)}$. Generally, in comparison with previous reports, the levels of Mn were higher (n.d.$\left.0.0252 \mu \mathrm{g} / \mathrm{g}^{20)}\right) ; 0.0065 \mu \mathrm{g} / \mathrm{g}^{25)} ; 0.04 \mu \mathrm{g} / \mathrm{g}^{21)}$, independently of the type of oil. Na was present in the range of $0.11 \pm 0.02$ and $0.87 \pm 0.01 \mathrm{mg} / \mathrm{g}$ in the olive oil samples. Com 2 and Com 3 presented similar values to the monovarietal samples, while all the other commercial samples contained higher $\mathrm{Na}$ amounts. Nevertheless, all the olive oil samples studied contain higher values of $\mathrm{Na}$, comparing to the previous reports $\left(0.02 \mathrm{mg} / \mathrm{g}^{18)} ; 0.0527-0.0665 \mathrm{mg} / \mathrm{g}^{19)} ; 0.0087\right.$ $\left.\mathrm{mg} / \mathrm{g}^{21)}\right)$.

The higher quantities observed for these quality parameters, as well as some differences between samples, are possibly influenced by the chemical composition of the foliar fertilizers used, which can contain K, Fe, Mg, Mn and Zn in different proportions. Nevertheless, these treatments are dependent on specific needs of each orchard, which can vary with the geographical location, or with the distinct meteorological conditions observed in each crop. Therefore, a cautious approach has to be taken when mentioning this influence, whereas in none of the referred works the informations regarding these treatments are stated, or their influence is taken into account ${ }^{20-26)}$.

$\mathrm{Zn}$ is fundamental for normal growth and survival of plants and animals as it plays a key role in the enzymatic activity in the human body. However, in excessive concentrations it could be toxic for all forms of life $\mathrm{e}^{26)}$. The $\mathrm{Zn}$ levels varied between not detectable and $20.0 \mathrm{E}^{-3} \pm 1.0 \mathrm{E}^{-4}$ $\mathrm{mg} / \mathrm{g}$. The quantities detected in the olive oil samples were higher than those previously reported in commercial olive oils $\left(0.1 \mathrm{E}^{-3} \mathrm{mg} / \mathrm{g}^{19)} ; 0.0523 \mathrm{E}^{-3} \mathrm{mg} / \mathrm{g}^{25)} ; 0.09 \mathrm{E}^{-3} \mathrm{mg} / \mathrm{g}^{23)}\right.$; $\left.0.1 \mathrm{E}^{-3} \mathrm{mg} / \mathrm{g}^{21)}\right)$, a difference that, as aforementioned, might be related to the fertilizers used for increasing the olive production. The recommended daily intakes of zinc are $15.0 \mathrm{mg} \mathrm{Zn}$ for adult males and $12.0 \mathrm{mg} \mathrm{Zn}$ for adult females ${ }^{27)}$, meaning that all the results obtained are safely under the limit, respecting a normal daily olive oil intake, and accounting with the contribution from a diversity of sources for the total $\mathrm{Zn}$ intake.

Table 3 presents the results for the determination of three elements, $\mathrm{Al}, \mathrm{Cd}$ and $\mathrm{Pb}$, often referred to as safety parameters, which, according to Flora and Pachauri ${ }^{28)}$ 


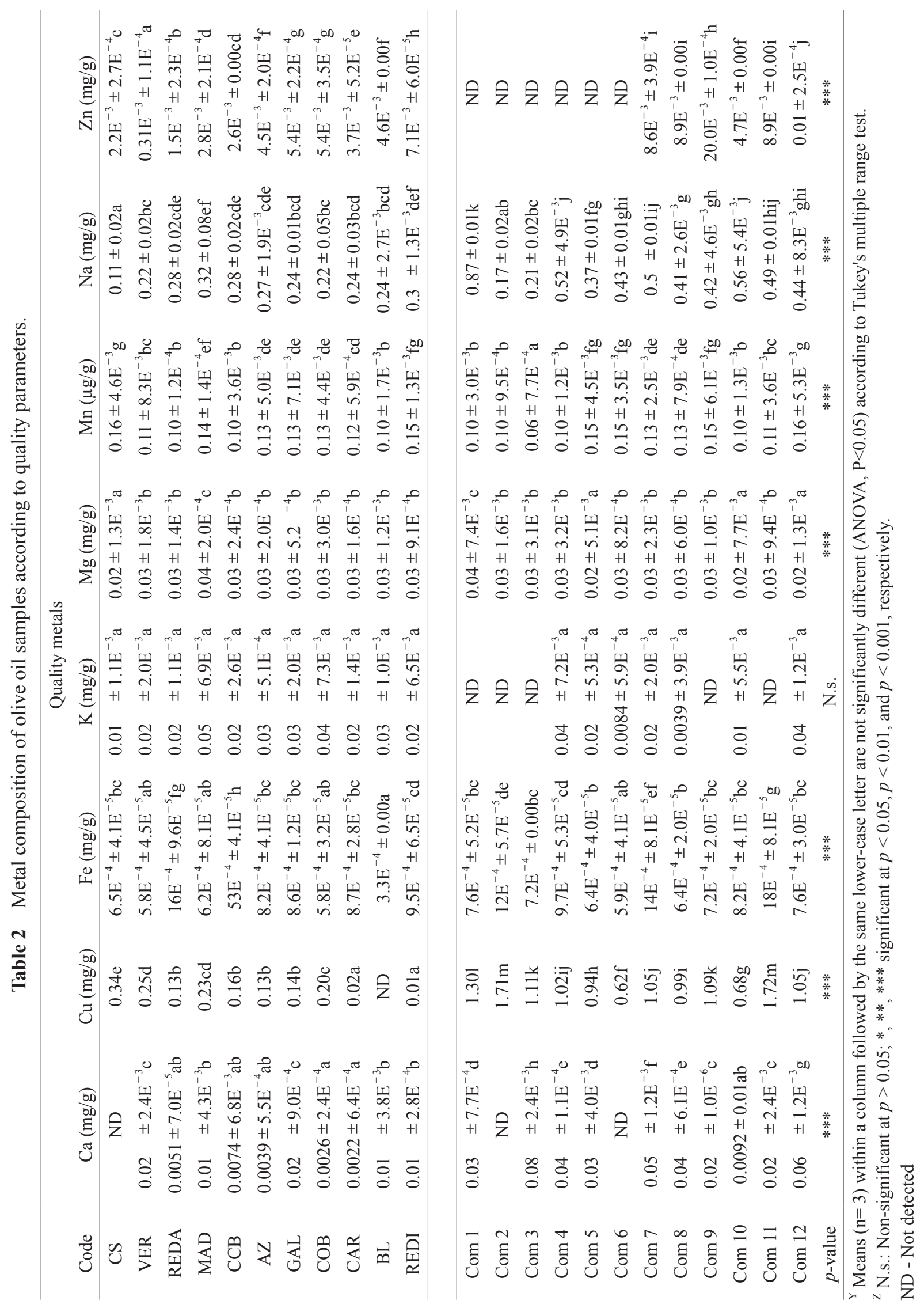


Table 3 Metal composition of olive oil samples according to safety parameters.

\begin{tabular}{cccc}
\hline \multicolumn{3}{c}{ Safety Metals } \\
\hline Code & $\mathrm{Al}(\mu \mathrm{g} / \mathrm{g})$ & \multicolumn{1}{c}{$\mathrm{Cd}(\mu \mathrm{g} / \mathrm{g})$} & $\mathrm{Pb}(\mu \mathrm{g} / \mathrm{g})$ \\
\hline CS & $3.830 \pm 0.315 \mathrm{~b}$ & $0.633 \pm 0.027 \mathrm{hi}$ & $0.030 \pm 0.003 \mathrm{a}$ \\
VER & $0.178 \pm 0.001 \mathrm{a}$ & $0.644 \pm 0.059 \mathrm{hi}$ & $0.089 \pm 0.001 \mathrm{abc}$ \\
REDA & $19.150 \pm 1.3441$ & $0.553 \pm 0.020 \mathrm{efgh}$ & $0.062 \pm 0.001 \mathrm{abc}$ \\
MAD & $21.655 \pm 1.502 \mathrm{p}$ & $0.615 \pm 0.004 \mathrm{gh}$ & $0.067 \pm 0.005 \mathrm{abc}$ \\
CCB & $4.715 \pm 0.401 \mathrm{c}$ & $0.771 \pm 0.002 \mathrm{kl}$ & $0.040 \pm 0.005 \mathrm{ab}$ \\
AZ & $9.327 \pm 0.812 \mathrm{f}$ & $0.830 \pm 0.005 \mathrm{klm}$ & $0.088 \pm 0.001 \mathrm{abc}$ \\
GAL & ND & $1.019 \pm 0.007 \mathrm{o}$ & $0.070 \pm 0.006 \mathrm{abc}$ \\
COB & $22.775 \pm 1.733 \mathrm{q}$ & $0.728 \pm 0.003 \mathrm{ij}$ & $0.067 \pm 0.006 \mathrm{abc}$ \\
CAR & $15.355 \pm 0.890 \mathrm{i}$ & $0.835 \pm 0.0131 \mathrm{~m}$ & $0.062 \pm 0.006 \mathrm{abc}$ \\
BL & $14.844 \pm 0.978 \mathrm{v}$ & $0.257 \pm 0.014 \mathrm{ab}$ & $0.116 \pm 0.004 \mathrm{bcd}$ \\
REDI & $8.667 \pm 0.501 \mathrm{e}$ & $0.832 \pm 0.036 \mathrm{~lm}$ & $0.114 \pm 0.005 \mathrm{bcd}$ \\
\hline & & & \\
\hline Com 1 & $27.021 \pm 1.589 \mathrm{t}$ & $0.990 \pm 0.029 \mathrm{no}$ & $0.181 \pm 0.002 \mathrm{def}$ \\
Com 2 & $19.543 \pm 0.958 \mathrm{~m}$ & $0.909 \pm 0.045 \mathrm{mn}$ & $0.280 \pm 0.001 \mathrm{ghi}$ \\
Com 3 & $14.738 \pm 0.744 \mathrm{~h}$ & $0.726 \pm 0.053 \mathrm{ij}$ & $0.225 \pm 0.004 \mathrm{fgh}$ \\
Com 4 & $17.897 \pm 1.003 \mathrm{k}$ & $0.212 \pm 0.021 \mathrm{a}$ & $0.186 \pm 0.01 \mathrm{def}$ \\
Com 5 & $20.915 \pm 0.996 \mathrm{o}$ & $0.356 \pm 0.029 \mathrm{bc}$ & $0.222 \pm 0.003 \mathrm{efg}$ \\
Com 6 & $24.986 \pm 1.003 \mathrm{~s}$ & $0.467 \pm 0.055 \mathrm{de}$ & $0.180 \pm 0.006 \mathrm{def}$ \\
Com 7 & $20.402 \pm 0.892 \mathrm{n}$ & $0.387 \pm 0.034 \mathrm{~cd}$ & $0.311 \pm 0.003 \mathrm{i}$ \\
Com 8 & $7.660 \pm 0.546 \mathrm{~d}$ & $0.464 \pm 0.017 \mathrm{de}$ & $0.327 \pm 0.007 \mathrm{i}$ \\
Com 9 & $14.249 \pm 1.002 \mathrm{~g}$ & $0.459 \pm 0.017 \mathrm{cde}$ & $0.308 \pm 0.001 \mathrm{hi}$ \\
Com 10 & $16.250 \pm 0.855 \mathrm{j}$ & $0.509 \pm 0.031 \mathrm{ef}$ & $0.291 \pm 0.002 \mathrm{ghi}$ \\
Com 11 & $23.409 \pm 0.641 \mathrm{r}$ & $0.520 \pm 0.025 \mathrm{efg}$ & $0.175 \pm 0.004 \mathrm{def}$ \\
Com 12 & $27.091 \pm 1.064 \mathrm{u}$ & $0.591 \pm 0.043 \mathrm{fgh}$ & $0.141 \pm 0.003 \mathrm{cde}$ \\
$p$-value & $* * *$ & $* * *$ & $* * *$ \\
\hline reas & $3)$ & & \\
\hline
\end{tabular}

${ }^{\mathrm{Y}}$ Means $(\mathrm{n}=3)$ within a column followed by the same lower-case letter are not significantly different (ANOVA, $\mathrm{P}<0.05$ ) according to Tukey's multiple range test.

${ }^{\mathrm{Z}}$ N.s.: Non-significant at $p>0.05 ; *, * *, * * *$ significant at $p<0.05, p<0.01$, and $p<0.001$, respectively.

ND - Not detected

present no beneficial effects. The $\mathrm{Al}$ concentrations ranged between not detected (n.d.) and $27.091 \mu \mathrm{g} / \mathrm{g}$, being generally higher in the commercial samples (Table 3). Cindric et $a l .{ }^{23)}$ that investigate this content in commercial extra virgin olive oils reported a value of $1.04 \mu \mathrm{g} / \mathrm{g}$, however, there are no further reports in this type of material. Even though the values presently registered are significantly higher than those observed by Cindric et collaborators, the recommendations of EFSA point to a maximum limit of 1.0 mg / kg of body weight, per week (known as TWI, Tolerable Weekly Intake), thus, the presently observed quantities being negligible, if we regard the bioavailability of $0.1 \%$ of the $\mathrm{Al}$ present in foodstuffs ${ }^{29)}$.

Regarding $\mathrm{Cd}$, this element is related to a plethora of adverse effects in human health, however, kidney is the main organ affected when exposed to high levels of this element ${ }^{28)}$. There are various sources of $\mathrm{Cd}$ exposure in humans, such as phosphate fertilizers, fossil fuel combustion, iron and steel production or natural sources. The Cd level in monovarietal and commercial olive oil samples were similar, ranging between $0.257 \pm 0.014$ and $1.019 \pm$ $0.007 \mu \mathrm{g} / \mathrm{g}$ and, $0.212 \pm 0.021$ and $0.990 \pm 0.029 \mu \mathrm{g} / \mathrm{g}$, re- 
spectively. These values are higher than those previously reported either in commercial or in monovarietal olive oils by Pehlivan et $a l .{ }^{25)}(0.0028 \mu \mathrm{g} / \mathrm{g})$, Cindric et $a l .{ }^{23)}(0.05 \mu \mathrm{g} /$ $\mathrm{g})$ and Benincasa et $a l^{20)} ;(0.00008-0.000366 \mu \mathrm{g} / \mathrm{g})$. However, Zhu et al., which assessed commercial olive oils $^{24)}$, reported Cd content of $2.64 \mu \mathrm{g} / \mathrm{g}$, which are higher than those detected in the present work.

Respecting health recommendations and guidelines concerning Cadmium, EFSA points to a TWI of $2.5 \mu \mathrm{g}$, whilst a provisional tolerable monthly intake (PTMI) of $25.0 \mu \mathrm{g} / \mathrm{kg}$ b.w. was recommended by the joint FAO/WHO Expert Committee on Food Additives (JECFA) in $2010^{30}$. In this regard, and accounting with the daily intake of olive oil by consumers, and other potential sources of $\mathrm{Cd}$, the values presently observed might constitute a concern, though the discrepancy between the distinct recommendations points to an uncertainty respecting the harmful doses of this metal. Therefore, efforts need to be made, in order, not only to monitor the origin and quantities of this metal in olive oils of different or origins, but also to fully understand the real doses of Cd that may constitute a health risk.

$\mathrm{Pb}$ is a metal element that can cause several symptoms related to its toxic effect, such as: hypertension, anemia, neurophysical defects, renal damage or even poisoning ${ }^{28)}$. The $\mathrm{Pb}$ content varied among the monovarietal and commercial samples, with the highest monovarietal sample values $(0.116 \pm 0.004 \mu \mathrm{g} / \mathrm{g})$ being lower than the lowest commercial sample values $(0.141 \pm 0.003 \mu \mathrm{g} / \mathrm{g})$. The $\mathrm{Pb}$ values were similar to those reported by Pehlivan et al. ${ }^{25)}$, and higher than those reported by Zhu et al. ${ }^{24)}$, both studies in commercial samples. Respecting guidelines, concerning the intake of $\mathrm{Pb}$, the former provisional TWI(25.0 $\mu \mathrm{g}$ ), was set aside by EFSA, due to the lack of comprehension of the dose-response relationships behind the adverse effects of this metal for the human health ${ }^{31}$. Still, a recommendation is made, so that further work should be done, in order to reduce exposure to $\mathrm{Pb}$, from both dietary and non-dietary sources.

High levels of metals, possibly representing an health issue, can be assigned to several origins, such as: soil, treatments, and milling equipment, which urge to be attended and regulated so consumers may be protected against harmful exposure, while the existent guidelines refer only to their intakes, neglecting the contents of these metals in specific foodstuffs. Also, further efforts should be made to increase the understanding of their dose-response relationship.

\subsection{Principal Components and Cluster Analyses}

The cluster analysis performed, resorting to the values obtained for all the trace elements assessed, is presented in Fig. 1. The Cluster analysis clearly separates the type of

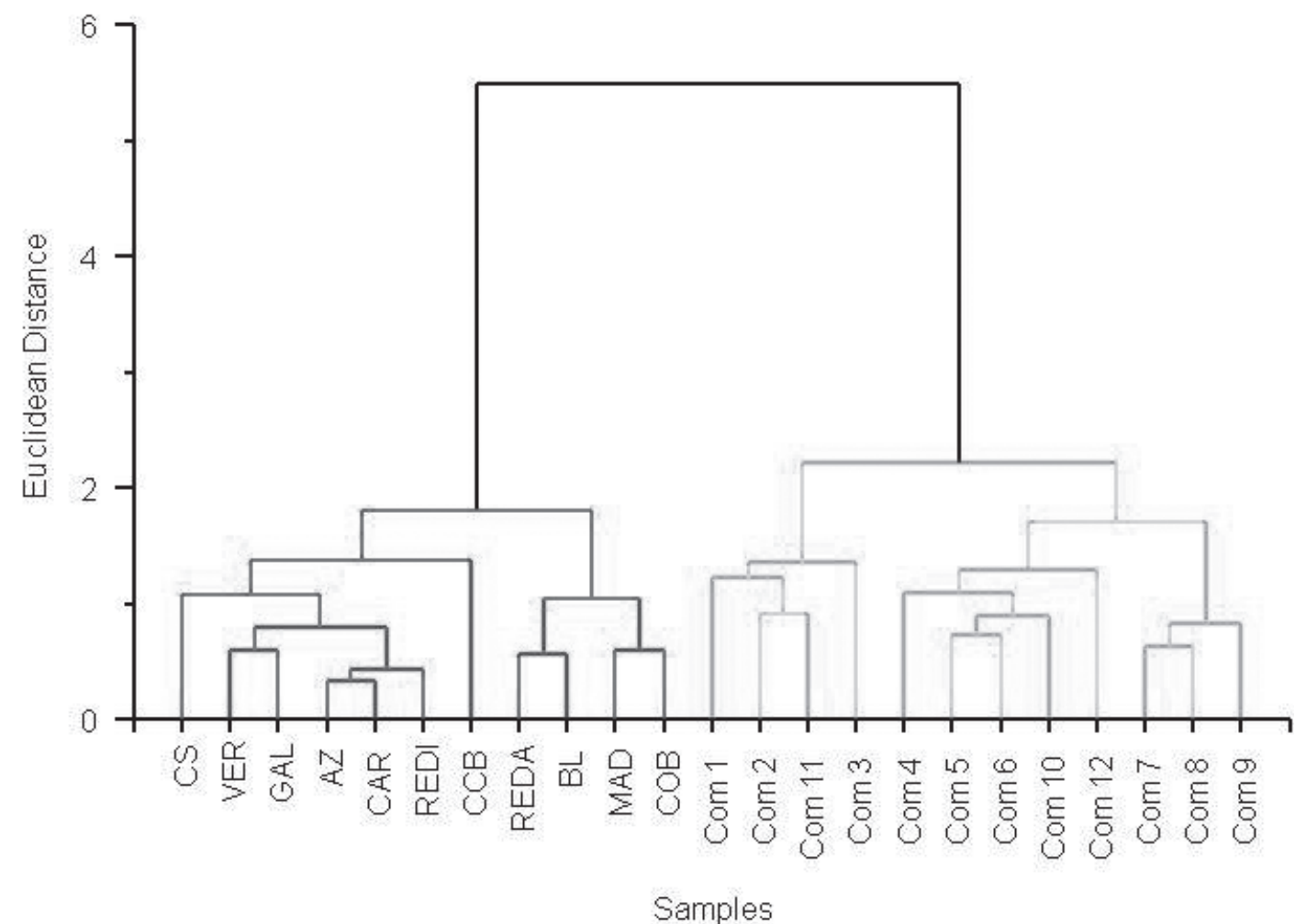

Fig. 1 Cluster analysis using the data collected for all the trace elements assessed ( $\mathrm{Na}, \mathrm{K}, \mathrm{Ca}, \mathrm{Cu}, \mathrm{Mg}, \mathrm{Fe}, \mathrm{Zn}, \mathrm{Mn}, \mathrm{Al}$, $\mathrm{Cd}$ and $\mathrm{Pb})$. 
oils, with the first branch being composed exclusively of monovarietal olive oils whereas the second branch presents only commercial olive oil samples. This may denote that the production scale can influence the chemical composition, pointing to possible contaminations during the transformation and processing procedures.

Respecting each one of these two clusters, one corresponding to each branch, some correlations between varietal geographical origin and separation between the samples can be pointed. For instance, respecting the cluster formed by the movovarietal olive oil samples, where three distinct subgroups can be discerned, one is formed by those cultivars with origin in Alentejo, exception made to BL, from North Alentejo, which is found together with

a)

․ Commercial olive oils

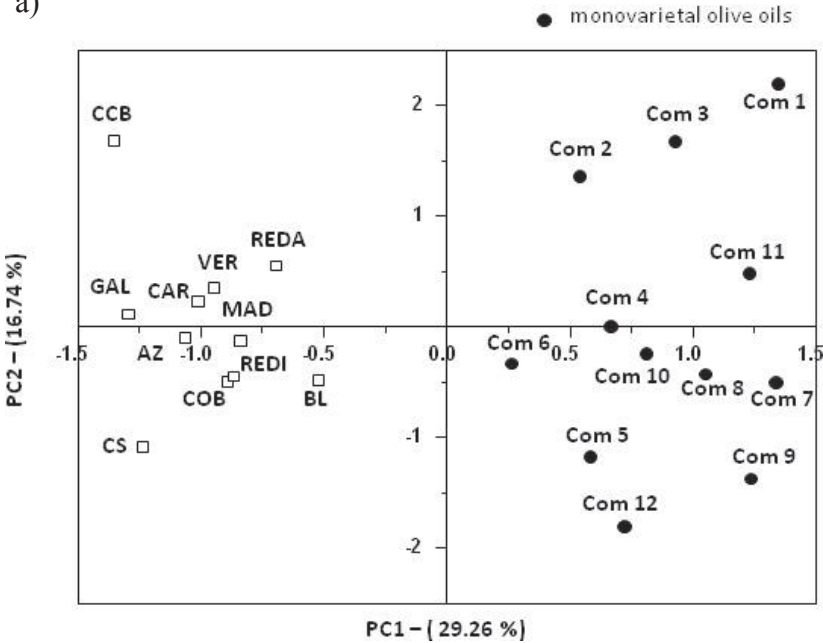

PC1 - (29.26\%)

c)

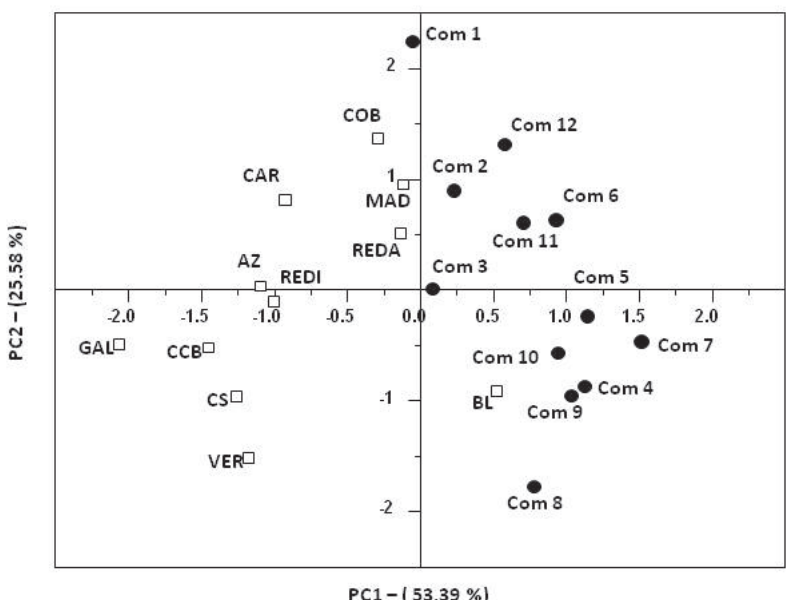

the cultivars from the Trás-os-Montes region. Furthermore, the single cultivar from Beira Interior, CCB, is found apart within the same cluster, forming a subgroup by itself.

Concerning the commercial olive oils, three subgroups are also distinguishable, one integrating three of the samples with PDO Trás-os-Montes (Com 7, 8 and 9), while the other two samples with the same PDO (Com 6 and 12) are found in another subset, together with three other samples with undifferentiated origin. Furthermore, the two commercial olive oil samples from biological agriculture (Com 7 and 8) are closely related, what is expectable since both of them presented similar production methodologies and the olive orchards belong to the same region(Fig. 1). Respecting Com 11, the only sample with PDO Alentejo, is

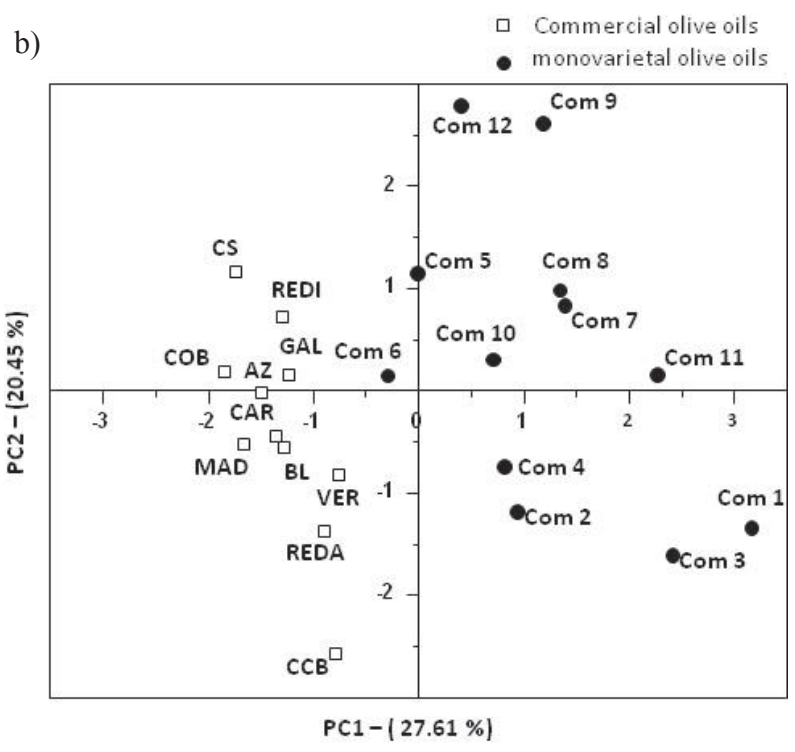

Fig. 2 Plots of the scores of PC1 vs. PC2, retrieved from the distinct PCA analyses. a) PCA analysis resorting to the quantities of all the trace elements accessed; b) PCA undertaken with the trace elements corresponding to quality parameters $(\mathrm{Na}, \mathrm{K}, \mathrm{Ca}, \mathrm{Cu}, \mathrm{Mg}, \mathrm{Fe}, \mathrm{Zn}, \mathrm{Mn})$; c) PCA undertaken with the trace elements corresponding to safety parameters $(\mathrm{Al}, \mathrm{Cd}, \mathrm{Pb})$. 
found in a third subgroup, along with three other samples without established origin. These observations, point to the potential of this approach to assess the geographical origin in olive oils, both monovarietal and commercial samples, as it has been observed when molecular markers were used, in a previous study ${ }^{32)}$.

Additionally, from the first PCA, performed with the values registered for all the elements assessed, it can be readily seen that the first principal component $(\mathrm{PC})$ extracted, PC1, explaining $29.26 \%$ of the variance between samples, separates the commercial samples, from the monovarietal ones, which present negative scores respecting this PC (Fig. 2a). Furthermore, within the same analysis, respecting $\mathrm{PC2}$, all the commercial samples from Trás-osMontes (Com 6, 7, 8, 9 and 12) present negative scores, while the monovarietal sample CCB presents detached the highest score amongst these samples, comparable only to the commercial samples Com 1, 2 and 3.

The visible separation between commercial and monovarietal, respecting $\mathrm{PC} 1$, is due to the greater quantities of $\mathrm{Na}, \mathrm{Pb}$ and $\mathrm{Cu}$ observed for the former samples, since these metals are the ones that weight the most for this PC (Table 4), with $\mathrm{Cu}$ presenting the greatest loading amongst the quality parameters $(0.4895$, Table 4$)$, while $\mathrm{Pb}$ is the most representative from the security parameters (0.4882), both constituting the most important variables for this separation. Furthermore, as aforementioned, there are clear differences, respecting these metals, between monovarietal and commercial olive oils, besides, also for $\mathrm{Na}$, the third most important variable (0.3847), distinct trends are observed, respecting the two kinds of samples (Table 2).

Respecting PC2 (16.74\% of variance), the negative scores observed for the commercial samples with PDO Trás-os-Montes are due to the high quantities of Mn and $\mathrm{Zn}$, alongside with low content in $\mathrm{Cd}$, relative to the other commercial samples; it has to be pointed that $\mathrm{Mn}$ and $\mathrm{Zn}$ contribute negatively to this $\mathrm{PC}(-0.5828$ and -0.390 , respectively), while Cd displays a positive loading of 0.3751 . The latter metal is the responsible for the high scores observed for samples Com 1, 2 and 3, while the highest score for $\mathrm{PC} 2$, respecting the monovarietal samples, observed for $\mathrm{CCB}$, is due to its high content in Fe, metal with a loading of 0.3180 for this component (Tables 2 and 4 ).

In Fig. 2b, the plot of the scores for the components PC1 vs. $\mathrm{PC} 2$, extracted from the second PCA, undertaken with the quality parameters only, is depicted. Again, PC1 (27.61\% of variance) separates the monovarietal samples to negative scores, from the commercial samples, which present positive scores. In this case, higher values for $\mathrm{Cu}$, $\mathrm{Ca}$ and $\mathrm{Na}$, registered for the commercial samples, are the reason for the differentiation, since these metals are the ones with greatest positive loadings, respecting PC1 (0.5897, 0.4541 and 0.4232 for $\mathrm{Cu}, \mathrm{Na}$ and $\mathrm{Ca}$, respectively), while negative score observed for Com 6 is due their low quantity of $\mathrm{Cu}$, along with the absence of $\mathrm{Ca}$. Besides the lower quantities of these metals, the monovarietal samples present higher values of $\mathrm{K}$, which presents a negative loading, respecting $\mathrm{PC} 1(-0.4248)$, contributing to

Table 4 Loadings extracted for the three first Principal Components obtained from each of the multivariate analyses undertaken.

\begin{tabular}{cccccccccc}
\hline & \multicolumn{3}{c}{${ }^{\mathrm{a}}$ All trace Elements } & \multicolumn{3}{c}{${ }^{\mathrm{b}}$ Quality parameters } & \multicolumn{3}{c}{${ }^{\mathrm{c}}$ Safety parameters } \\
\cline { 2 - 9 } & ${ }^{\mathrm{d}} \mathrm{PC} 1$ & $\mathrm{PC} 2$ & $\mathrm{PC} 3$ & $\mathrm{PC} 1$ & $\mathrm{PC} 2$ & $\mathrm{PC} 3$ & $\mathrm{PC} 1$ & $\mathrm{PC} 2$ & $\mathrm{PC} 3$ \\
& ${ }^{\mathrm{C}}(29,62 \%)$ & $(16,74 \%)$ & $(12,50 \%)$ & $(27,61 \%)$ & $(20,45 \%)$ & $(13,70 \%)$ & $(53,39 \%)$ & $(25,58 \%)$ & $(21,03 \%)$ \\
\hline $\mathrm{Ca}$ & 0.3314 & 0.0093 & -0.0059 & 0.4232 & 0.1287 & 0.1760 & - & - & - \\
$\mathrm{Cu}$ & 0.4895 & 0.1184 & -0.0960 & 0.5897 & 0.1259 & -0.1136 & - & - & - \\
$\mathrm{Fe}$ & -0.1063 & 0.3180 & -0.2484 & 0.0031 & -0.3568 & -0.4412 & - & - & - \\
$\mathrm{K}$ & -0.2789 & -0.2602 & 0.5132 & -0.4248 & 0.0363 & 0.4990 & - & - & - \\
$\mathrm{Mg}$ & -0.0186 & 0.4158 & 0.4057 & 0.0853 & -0.3924 & 0.6016 & - & - & - \\
$\mathrm{Mn}$ & -0.0837 & -0.5828 & 0.0424 & -0.2681 & 0.6132 & 0.0604 & - & - & - \\
$\mathrm{Na}$ & 0.3837 & 0.0892 & 0.3199 & 0.4541 & 0.0849 & 0.3819 & - & - & - \\
$\mathrm{Zn}$ & 0.1534 & -0.3900 & -0.2310 & 0.0858 & 0.5495 & -0.0315 & - & - & - \\
$\mathrm{Al}$ & 0.3163 & -0.0244 & 0.5384 & - & - & - & 0.5330 & 0.8273 & -0.1775 \\
$\mathrm{Cd}$ & -0.2123 & 0.3751 & -0.1000 & - & - & - & -0.5859 & 0.5122 & 0.6280 \\
$\mathrm{~Pb}$ & 0.4882 & -0.0572 & -0.2091 & - & - & - & 0.6105 & -0.2307 & 0.7577 \\
\hline
\end{tabular}

${ }^{a}$ Loadings corresponding to the PCA analysis resorting to the quantities of all the trace elements accessed;

${ }^{\mathrm{b}}$ Loadings corresponding to the PCA undertaken with the trace elements corresponding to quality parameters;

${ }^{\mathrm{c}}$ Loadings corresponding to the PCA undertaken with the trace elements corresponding to safety parameters;

d number of the PC represented in each column;

${ }^{\mathrm{e}}$ Variance explained by the corresponding Principal Component. 
their negative scores (Table 4). Respecting PC2 (20.45\% of variance), all the commercial samples with PDO Trás-osMontes display positive scores (Fig. 2b), due the high quantities of $\mathrm{Zn}$, alongside with relatively high contents of $\mathrm{Mn}$ (Table 2), both these components representing the most important variables for this component, with a loading of 0.6132 for the latter, and 0.5495 for the former.

Furthermore, another PCA has been undertaken, resorting only to the metals denoted as security parameters (Fig. 2c). Again, this approach allowed to distinguish the commercial samples, from the monovarietal ones, the first group being mainly separate due to the higher contents in $\mathrm{Pb}$ and $\mathrm{Al}$ with loadings of 0.6105 and 0.5330 , respectively, for $\mathrm{PC} 1$ (53.39\% of variance), while the monovarietal samples are related to higher contents in $\mathrm{Cd}$, with a loading of -0.5859 for the same principal component(Table 4). In this case, Com 1 and BL constitute the only exceptions, being apart from their respective sets, the first, in the negative half of $\mathrm{PC1}$, due to its high content in $\mathrm{Cd}$, while $\mathrm{BL}$ is found amongst the commercial samples due to their low $\mathrm{Cd}$ and high $\mathrm{Pb}$ contents (Table 3).

This approach clearly separated the type of olive oil production, besides retrieving some indications about geographical origin, even if the number of samples assessed is not comprehensive for that purpose. Therefore, an interesting by-product arises from the present work, since the use of this combined methodology, alongside with the resort to other chemical parameters displays potential for the development of a reliable methodology for geographical determination.

\section{CONCLUSION}

Regarding quality parameters, the monovarietal olive oils display larger quantities of $\mathrm{Mg}, \mathrm{Fe}, \mathrm{Mn}$, while the commercial samples are characterized by greater amounts of $\mathrm{Na}$, $\mathrm{Ca}, \mathrm{Cu}$ and $\mathrm{Zn}$. Furthermore, concerning $\mathrm{Al}$ and $\mathrm{Pb}$ values, which constitute safety parameters, the commercial olive oils presented higher values than the monovarietal samples, and lower quantities of $\mathrm{Cd}$. Though the quantities of $\mathrm{Al}$ and $\mathrm{Pb}$ are very low, comparing to the Tolerable Weekly Intake, the quantities of Cd observed might constitute an issue, and should be monitored hereafter.

The differentiation of olive oils according to their production scale was achieved using the trace elements characterized, coupled to multivariate statistical analysis methods, with some indications, regarding geographical origin being also discerned, pointing to the potential of this methodology for the assessment of the geographical origin of olive oils, besides clearly distinguishing the type of oil production.

\section{Acknowledgement}

This work was supported by the Projects 'Post-Doc grant SFRH/BPD/70378/2010 to SG and PhD grant SFRH/ BD/78013/2011 to IG from the Fundação para a Ciência e Tecnologia and by Pest-OE/AGR/UI4033/2014.

This work was supported by the Project INNOFOOD INNOvation in the FOOD sector through the valorization of food and agro-food by-products - NORTE-07-0124-FEDER-0000029, financed by the North Portugal Regional Operational Programme(ON.2 - O Novo Norte) under the National Strategic Reference Framework (QREN), through FEDER, as well as by PIDDAC through FCT/MEC, and by the project PEst-OE/AGR/UI4033/2014.

\section{References}

1) Covas, M. I.; Konstantinidou, V.; Fitó, M. Olive oil and cardiovascular health. J. Cardiovasc. Pharmacol. 54, 477-482 (2009).

2) EC. (2006a). Section 3-Metals, item 3.1.14. Official Journal of the European Union, $\mathrm{N}^{\circ} 1881 / 2006$, p. 21.

3) Souza, R. M.; Mathias, B. M.; Silveira, C. L. P.; Aucelio, R. Q. Inductively coupled plasma optical emission spectrometry for trace multi-element determination in vegetable oils, margarine and butter after stabilization with propan-1-ol and water. Spectrochim. Acta B 60, 711-715 (2005).

4) Jamali, M. K.; Kazi, T. G.; Arain, M. B.; Afridi, H. I.; Jalbani, N.; Sarfraz, R. A.; Baig, J. A. A multivariate study: variation in uptake of trace and toxic elements by various varieties of Sorghum bicolor L. J. Hazard. Mater. 158, 644-651 (2008).

5) Matos, M. N.; Campos, R. C. Determination of copper and nickel in vegetable oils by direct sampling graphite furnace atomic absorption spectrometry. Talanta 70, 929-932 (2006).

6) Gopalani, M.; Shahare, M.; Ramteke, D. S.; Wate, S. R. Heavy metal content of potato chips and biscuits from Nagpur city, India. B. Environ. Contam. Tox. 79, 384-387 (2007).

7) Benedet, J. Á.; Shibamoto, T. Role of Transition Metals, $\mathrm{Fe}$ (II), $\mathrm{Cr}$ (II), $\mathrm{Pb}$ (II), and $\mathrm{Cd}$ (II) in Lipid Peroxidation. Food Chem. 107, 165-168(2008).

8) García-González, D.; Luna, G.; Morales, M.; Aparicio, R. Stepwise geographical traceability of virgin olive oils by chemical profiles using artificial neural network models. Eur. J. Lipid Sci. Tech. 111, 1003-1013 (2009).

9) Beltrán, M.; Sánchez-Astudillo, M.; Aparicio, R.; García-Gonzalez, D. L. Geographical traceability of virgin olive oils from south-western Spain by their multi-elemental composition. Food Chem. 169, 350-357 
(2015).

10) Camin, F.; Larcher, R.; Nicolini, G.; Bontempo, L.; Bertoldi, D.; Perini, M.; Schlicht, C.; Schellenberg, A.; Thomas, F.; Heinrich, K.; Voerkelius, S.; Horacek, M.; Ueckermann, H.; Froeschl, H.; Wimmer, B.; Heiss, G.; Baxter, M.; Rossmann, A.; Hoogewerff, J. Isotopic and Elemental Data for Tracing the Origin of European Olive Oils. J. Agr. Food Chem. 58, 570-577 (2010).

11) Karabagias, I.; Michos, C.; Badeka, A.; Kontakos, S.; Stratis, I.; Kontominas, M. G. Classification of Western Greek virgin olive oils according to geographical origin based on chromatographic, spectroscopic, conventional and chemometric analyses. Food Res. Int. 54, 19501958 (2013).

12) Zeiner, M.; Stefan, I.; Cindric, I. J. Determination of trace elements in olive oil by ICP-AES and ETA-AAS: A pilot study on the geographical characterization. $M i$ crochem. J. 81, 171-176 (2005).

13) Ieggli, C. V. S.; Bohrer, D.; Do Nascimento, P. C.; De Carvalho, L. M. Flame and graphite furnace atomic absorption spectrometry for trace element determination in vegetable oils, margarine and butter after sample emulsification. Food Addit. Contam. 28, 640-648 (2011).

14） Mildner-Szkudlarz, S.; Jelén, H. H. The potential of different techniques for volatile compounds analysis coupled with PCA for the detection of the adulteration of olive oil with hazelnut oil. Food Chem. 110, 751-761 (2008).

15) Fragaki, G.; Spyros, A.; Siragakis, G.; Salivaras, E.; Dais, P. Detection of Extra Virgin Olive Oil Adulteration with Lampante Olive Oil and Refined Olive Oil Using Nuclear Magnetic Resonance Spectroscopy and Multivariate Statistical Analysis. J. Agr. Food Chem. 53, 2810-2816 (2005).

16) Gouvinhas, I.; Almeida, J.; Carvalho, T.; Machado, N.; Barros, A. Discrimination and characterization of extra virgin olive oils from three cultivars in different maturation stages using Fourier transform infrared spectroscopy in tandem with chemometrics. Food Chem. 174, 226-232 (2015).

17) Morrison DF. - Multivariate Statistical Methods, 3rd McGraw Hill, New York (1990).

18) DTU-TCAD - Table of Food Composition of Denmark. National Food Institute-Technical University of Denmark DTU 2001. Consulted in internet in March 2011.

19) TCAF - Anses Table Ciqual Composition nutritionnelle des aliments 2008 (France). Consulted in http://www. afssa.fr/TableCIQUAL/PMP000QWI0.htm; March 2015.

20) Benincasa, C.; Lewis, J.; Perri, E.; Sindona, G.; Tagarelli, A. Determination of trace element in Italian virgin olive oils and their characterization according to geo- graphical origin by statistical analysis. Anal. Chim. Acta 585, 366-370 (2007).

21） Mendil, D.; Uluözlü, Ö. D.; Tüzen, M.; Soylak, M. Investigation of the Levels of Some Element in Edible Oil Samples Produced in Turkey by Atomic Absorption Spectrometry. J. Hazard. Mater. 165, 724-728 (2009).

22) Ashraf, W.; Mian, A. A. Levels of selected heavy metals in black tea varieties consumed in Saudi Arabia. Bull. Environ. Contam. Toxicol. 81, 101-104(2007).

23) Cindric, I. J.; Zeiner, M.; Steffan, I. Trace elemental characterization of edible oils by ICP-AES and GFAAS. Microchem. J. 85, 136-139 (2007).

24) Zhu, F.; Fan, W.; Wang, X.; Qu, L.; Yao, S. Health risk assessment of eight heavy metals in nine varieties of edible vegetable oils consumed in China. Food Chem. Toxicol. 49, 3081-3085(2011).

25) Pehlivan, E.; Arslan, G.; Gode, F.; Altun, T.; Özcan, M. Determination of some inorganic metals in edible vegetable oils by inductively coupled plasma atomic emission spectroscopy (ICP-AES). Grasas y Aceites 59, 239-244 (2008).

26) Fosmire, G. J. Zinc toxicity. Am. J. Clin. Nutr. 51, 225-227 (1990).

27) Mendil, D.; Tuzen, M. Assessment of trace elements in animal tissues from turkey. Environ. Monit. Assess. 182, 423-430 (2011).

28) Flora, S. J. S.; Pachauri, V. Chelation in Metal Intoxication. Int. J. Environ. Res. 7, 2745-2788(2010).

29) Aguilar, F.; Autrup, H.; Barlow, S.; Castle, L.; Crebelli, R.; Dekant, W.; Engel, K. H.; Gontard, N.; Gott, D.; Grilli. S.; Gürtler, R.; Larsen, J. C.; Leclercq, C.; Leblanc, J. C.; Malcata, F. X.; Mennes, W.; Milana, M. R.; Pratt, I.; Rietjens, I.; Tobback, P.; Toldrá, F. Safety of aluminium from dietary intake. EFSA J. 754, 1-34 (2008).

30) Alexander, J.; Benford, D.; Boobis, A.; Ceccatelli, S.; Cravedi, J. P.; Di Domenico, A.; Doerge, D.; Dogliotti, E.; Edler, L.; Farmer, P.; Filipič, M.; FinkGremmels, J.; Fürst, P.; Guérin, T.; Knutsen, H. K.; Machala, M.; Mutti, A.; Schlatter, J.R.; van Leeuwen, R. Statement on tolerable weekly intake for cadmium. EFSA J. 9(2), 1975 (2011).

31) Alexander, J.; Benford, D.; Boobis, A.; Ceccatelli, S.; Cravedi, J. P.; Di Domenico, A.; Doerge, D.; Dogliotti, E.; Edler, L.; Farmer, P.; Filipič, M.; FinkGremmels, J.; Fürst, P.; Guérin, T.; Knutsen, H. K.; Machala, M.; Mutti, A.; Schlatter, J. R.; van Leeuwen, R. Scientific Opinion on Lead in Food. EFSA J. 8(4), 1570 (2010).

32) Martins-Lopes, P.; Gomes, S.; Santos, E.; Guedes-Pinto, H. DNA markers for Portuguese olive oil fingerprinting. J. Agr. Food Chem. 56, 11786-11791 (2008). 